\title{
Sampling for lead in school drinking water: a review of protocols
}

\author{
Juliette O'Keeffe ${ }^{\mathrm{a} *}$, Anne-Marie Nicola ${ }^{\mathrm{a}}$ Prabjit Barn ${ }^{\mathrm{b}}$ and Lydia Ma ${ }^{\mathrm{a}}$ \\ ${ }^{a}$ National Collaborating Centre for Environmental Health (NCCEH) \\ ${ }^{\mathrm{b} B C}$ Centre for Disease Control (BCCDC)
}

\section{Introduction}

In 2019 Health Canada reduced the maximum allowable concentration (MAC) for lead in drinking water from $10 \mu \mathrm{g} / \mathrm{L}$ to $5 \mu \mathrm{g} / \mathrm{L}$. This signals a national commitment to protecting populations from the deleterious effects of lead and will be particularly important for vulnerable populations such as children. Canada is one of the first countries to lower the lead limit in drinking water below $10 \mu \mathrm{g} / \mathrm{L}$. The US Environmental Protection Agency (EPA) Action Limit is currently $15 \mu \mathrm{g} / \mathrm{L}$, and Australia and the European Commission (EC) use $10 \mu \mathrm{g} / \mathrm{L}$, with the $\mathrm{EC}$ indicating that lead limits in the Drinking Water Directive will be halved to $5 \mu \mathrm{g} / \mathrm{L}$ over a transitional period of 10 years (European Commission, 2018).

Even at low levels of lead, children are susceptible to neurodevelopmental effects including cognitive and behavioral impacts (Council on Environmental Health, 2016; Levallois et al., 2018). Drinking water is estimated to contribute up to $10 \%-40 \%$ of total lead exposure in children, with food and dust making up the remaining sources. Reducing lead in school water is therefore an important public health action to reduce exposure (Levallois et al., 2018; Verhougstraete et al., 2019). Younger children can spend a significant portion of their day in a school, particularly if their school day is extended through pre- and after-school care or extracurricular activities, which can result in increased consumption of school drinking water.

In light of Health Canada's new guidance on lead in drinking water, many jurisdictions will need to re-evaluate their current testing programs for compliance. Some provinces have already signalled their adoption of the new level and others are anticipated to follow. Over the past few years, testing programs in various provinces have used the now outdated $10 \mu \mathrm{g} / \mathrm{L}$ limit, and up to $20 \mu \mathrm{g} / \mathrm{L}$ has been used in some cases. Most sampling programs have been carried out in schools built before 1990, which are considered to have a higher likelihood of lead pipes and lead-containing fittings. Extensive sampling of newer buildings has not been undertaken; however, evidence of exceedances of the $10 \mu \mathrm{g} / \mathrm{L}$ limit in post-1990 buildings suggests that some newer schools may also be at risk of exceeding the new $5 \mu \mathrm{g} / \mathrm{L}$ limit, particularly at taps where lead-containing brass fittings are present and usage levels are low (Deshommes et al., 2016). A review of all school testing programs is now warranted.

Research shows that results of school lead testing vary not only because the properties of the source water can affect the leaching of lead, but also by the sampling protocols that are used for water collection for testing (Deshommes et al., 2016). Protocols can vary by the timing of collection, sampling locations, and volume and number of samples collected. These variables can impact the results and their interpretation. Having standardized approaches to sampling of school drinking water for lead is more important than ever to ensure results can be used for the protection of health.

The National Collaborating Centre for Environmental Health (NCCEH) and the BC Centre for Disease Control (BCCDC) undertook a review of several protocols that guide testing of lead in drinking water as recommended by Canadian and US government agencies. The review identifies important considerations for designing and undertaking sampling programs (National Collaborating Centre for Environmental Health, 2019). This article presents the highlights of the review.

\section{Occurrence of lead in water}

Lead is rarely found in source water but can enter drinking water by leaching from lead service lines, lead-lined steel pipes, and plumbing components such as soldered joints or leaded brass components. In Canada, lead was permitted for use in service lines and building plumbing up to 1975, and lead in solder was permitted for use until 1986. Newer buildings are unlikely to have lead pipes, but lead service lines and some components such as some brass fittings can still be a source of lead contamination in drinking water in these sites (Lei et al., 2018). Water that has been left stagnant in contact with lead pipes and plumbing components can accumulate a higher concentration of lead than flowing water. Disruption to pipe work and changes to plumbing during renovations can sometimes result in temporary increases in water lead levels if lead pipes or components are present. Water properties such as temperature, $\mathrm{pH}$, disinfectant residual and other chemical properties can influence the solubility of lead (Doré et al., 2018). Warm water can leach more lead than cold water, and low $\mathrm{pH}$ (slightly acidic) water can increase solubility of lead compared to water with more neutral $\mathrm{pH}$. Some jurisdictions add corrosion control inhibitors, such as orthophosphate, to reduce lead solubility, but a change to a more corrosive water source or change to corrosion control inhibitors in the water supply can affect lead leaching levels (Liu et al., 2017). 


\section{Sampling requirements in schools}

While there is a Canadian guideline for lead in drinking water, there is no federal policy that requires schools to test for lead in drinking water. Some provinces such as Ontario have adopted mandatory testing, whereas elsewhere requirements for testing may be on a voluntary basis or as directed by regional or First $\mathrm{Na}$ tions authorities. Two other provinces, Quebec and BC, require testing and the remaining provinces and territories have undertaken lead testing as a voluntary measure to ensure compliance with guideline limits or for investigative purposes. The sampling protocols examined in the NCCEH review include two from Health Canada (Health Canada, 2009, 2019) and one from provincial ministries in each of $\mathrm{BC}$, Quebec, and Ontario (British Columbia Ministry of Health, 2017; LegisQuebec, 2017; Ontario Ministry of the Environment, 2007). Two American protocols were also reviewed (California Environmental Protection Agency, 2018; United States Environmental Protection Agency, 2018). The following section examines the key features of the sampling protocols mentioned above.

\section{Sampling protocols}

The sampling protocols examined all provide a slightly different approach driven by the relevant sampling program objectives. The main objectives in the sampling protocols examined included:

- Assessment of typical exposure (Health Canada, 2019)

- Investigation of potential sources of contamination (Health Canada, 2009 and US EPA)

- Routine monitoring (Ontario, Quebec, and California EPA).

The different objectives result in different timing and frequency of sampling, location of sampling points, as well as sample procedures used. A summary of how these factors differ is provided below, with a full description of the protocols in the NCCEH report (National Collaborating Centre for Environmental Health, 2019).

\section{Timing and frequency}

The time of day, day of the week, and time of year can all influence the level of lead measured in a test sample and timing of sample collection may be adjusted to identify the worst- and best-case scenarios. For example, sampling at the end of an extended school break such as summer holidays when water lines have been stagnant will likely result in higher lead levels. Alternatively sampling at the end of the last day of school for the week when taps have been in constant use for multiple days may provide a better indication of the baseline typical exposure levels.

\section{Location}

The location of sampling can also result in variations in lead levels. Priority is often given to drinking water fountains, particularly frequently used outlets, and outlets used for food preparation. Knowledge of the age or make-up of the pipework may help to focus sampling on the most at-risk taps; however, sampling programs with a single sampling point or limited number of sampling points may not be adequate for the protection of health. An analysis of a program of lead testing in schools in the US found that the more taps tested, the more likely a problem was found (Cradock et al., 2019).

\section{Sample collection and outlet flushing}

Sample collection can vary by volume, number of samples collected, and how the sample is collected. Some protocols specify first-draw samples taken as the tap is turned on, usually following a specified period of stagnation. These samples can help to identify localised contamination. Flushed samples may also be taken in place of, or in addition to, first-draw samples. These are collected after a specified period of drawing water through the plumbing system. Flushed samples can give an indication of wider contamination issues in the plumbing system or service lines.

\section{Mitigation options}

Consistency and standardisation of sampling protocols used in schools can improve the potential for problems to be identified and mitigation actions to be implemented. The common mitigation measures for elevated lead in drinking water have varying levels of cost, disruption to normal operation of the premises, and effectiveness. Common actions are listed below.

\section{Actions at the treatment plant}

Many jurisdictions add corrosion control chemicals such as orthophosphate to their drinking water supply to reduce leaching of lead from pipes in the distribution network or buildings. Corrosion control is not typically a solution applied to address localized lead contamination and would require discussion with utility operators over system-wide solutions. Effectiveness of corrosion control chemicals requires monitoring by the water supplier, as changes in source waters can have an impact on the effectiveness of corrosion control chemicals.

\section{Removal of the contamination source}

Removing the source of the contamination is the most effective way of eliminating the risk of exposure. If taps or outlets are identified as the source of contamination, these can be changed relatively easily with minimal disruption and cost. Identification and removal of pipes and components within walls, floors, or ceilings will be more disruptive and costly. Where the source of the lead is the distribution or service lines outside the boundaries of the building, replacement becomes more difficult and may be outside the control of the building owner/operator.

\section{Introduction of routine pipe flushing}

An alternative to pipe replacement is to remove lead that has leached into stagnant water by flushing the pipes before use or consumption. The frequency and duration of flushing may affect the suitability of this measure. A popular approach used by lead 
management strategies in some US schools is a $30 \mathrm{~s}$ flush before use to eliminate stagnant water from piping (Sanborn and Carpenter, 2018). Other approaches may include weekly flushing of all drinking water outlets on the first school day of the week, flushing following school breaks, or a move towards automated flushing systems (Sanborn and Carpenter, 2018). However, evidence suggests that lead levels can return to preflush levels within hours of flushing; therefore, flushing may need to be undertaken throughout the day to keep lead levels at an acceptable level (Doré et al., 2018; Murphy, 1993). The flushing time needed to effectively reduce lead concentrations to acceptable levels may differ based the source of the lead contamination, the temperature, and the chemical properties of the water; not all issues can be solved by pipe flushing alone. Sampling protocols can be applied to assess the effectiveness of flushing programs. Manual flushing relies on allocation of staff time and resources, whereas automatic systems require the added cost of installation of valves and sensors. Both approaches to flushing result in wastage of water.

\section{Installation of point of entry (POE) or point of use (POU) treatment}

POE or POU treatment systems, such as reverse osmosis, activated carbon filters, or distillation systems, are effective in reducing lead concentrations (Verhougstraete et al., 2019). Treatment systems should be assessed for suitability for lead removal and properly sited to ensure placement after points of contamination. POE systems may be less effective if water entering the building is treated and subsequently distributed through pipes that will reintroduce contamination. Installation of POU systems may be more effective for a complex pipe system where the source of lead contamination is within the building's plumbing. For both POE and POU systems, routine inspection and servicing is required to ensure effectiveness of treatment is maintained.

\section{Avoidance or use of alternative water sources}

Avoidance measures or alternative sources may be considered where the mitigation solutions listed above are not practical or do not provide sufficient lead removal, although such measures may only be appropriate in the short term. Restriction on use at taps where lead components have been identified, or ensuring only cold water is used for drinking or food preparation can limit exposure in some cases. Provision of an alternative source for drinking or food preparation such as bottled water could be used either as single-use disposable bottles or use of refillable water coolers.

\section{Conclusion}

Reducing low-level exposure to lead through drinking water remains an important public health action to protect the health of children. Minimising exposure requires a reasoned approach to assessing exposure risks within school drinking water. With the new Health Canada MAC for lead in effect as of March 2019, many schools that previously recorded compliant results may need to revisit monitoring protocols or look to resample their drinking water outlets. Sampling of post-1990 schools may also be considered where lead-containing brass components could be present. The development of standardised and consistent approaches to sampling will improve confidence in sampling results and can assist decision makers in identifying the most appropriate mitigation measures for reducing exposure in affected schools. The primary consideration when applying any of these protocols or designing a new protocol is to have a clear definition of the sampling program objectives. Protocols should be designed to achieve the objectives and also be clear, consistent, and unambiguous. Lack of clarity on some aspects of the sampling protocol may lead to inaccurate assessment of potential lead exposure and inconsistent practices, thus limiting the potential for comparison, identification of trends, or confirmation of the effectiveness of mitigation measures.

\section{References}

British Columbia Ministry of Health. 2017. Interim guidelines on evaluating and mitigating lead in drinking water supplies, schools, daycares and other buidings. Victoria, BC: Ministry of Health, Health Protection Branch.

Council on Environmental Health. 2016. Prevention of childhood lead toxicity. Pediatrics. 138(1): 1-15. doi: 10.1542/peds.2016-1493.

California Environmental Protection Agency. 2018. Lead sampling of drinking water in California schools. Available at: https://www.waterboards.ca.gov/drinking_water/certlic/drinkingwater/leadsamplinginschools.shtml [accessed 9 January 2019].

Cradock, A., Hecht, C., Poole, M. K., Vollmer, L., Flax, C., \& Barrett, J. 2019. Early adopters. State approaches to testing school drinking water for lead in the United States. Berkeley, CA: Harvard T H Chan School of Public Health and the University of California Agriculture and Natural Resources, Nutrition Policy Institute.

Deshommes, E., Andrews, R. C., Gagnon, G., McCluskey, T., McIlwain, B., Doré, E., Nour, S., \& Prévost, M. 2016. Evaluation of exposure to lead from drinking water in large buildings. Water Res. 99: 46-55. doi: 10.1016/j.watres.2016.04.050.

Doré, E., Deshommes, E., Andrews, R. C., Nour, S., \& Prévost, M. 2018. Sampling in schools and large institutional buildings: Implications for regulations, exposure and management of lead and copper. Water Res. 140: 110-122. doi: 10.1016/j.watres.2018.04.045.

European Commission. 2018. Proposal for a Directive of the European Parliament and of the Council on the quality of water intended for human consumption (recast). (COM/2017/0753 final 2017/0332 (COD)). Brussels. Available at: https://eur-lex.europa.eu/ legal-content/EN/TXT/HTML/?uri=CELEX:52017PC0753\& from $=\mathrm{EN}$ [Accessed 27 March 2019]

Health Canada. 2009. Guidance on controlling corrosion in drinking water distribution systems. Ottawa, ON: Ministry of Health, Federal-Provincial-Territorial Committee on Drinking Water, Federal-Provincial-Territorial Committee on Health and the Environment.

Health Canada. 2019. Guidelines for Canadian drinking water quality: Guideline technical document - Lead. Ottawa, ON.

LegisQuebec. 2017. Regulation respecting the quality of drinking water (chapter Q-2, r. 40). Environmental Quality Act. Available at: http://legisquebec.gouv.qc.ca/en/ShowDoc/cr/Q-2,\%20r.\%2040 
Lei, I.-L., Ng, D.-Q., Sable, S. S., \& Lin, Y.-P. 2018. Evaluation of lead release potential of new premise plumbing materials. Environ Sci Pollut Res. 25(28): 27971-27981. doi: 10.1007/s11356-018-2816-2. [Accessed 1 March 2019]

Levallois, P., Barn, P., Valcke, M., Gauvin, D., \& Kosatsky, T. 2018. Public health consequences of lead in drinking water. Curr Environ Health Rep. 5(2): 255-262. doi: 10.1007/s40572-018-0193-0.

Liu, G., Zhang, Y., Knibbe, W.-J., Feng, C., Liu, W., Medema, G., \& van der Meer, W. 2017. Potential impacts of changing supply-water quality on drinking water distribution: A review. Water Res. 116: 135-148. doi: 10.1016/j.watres.2017.03.031.

Murphy, E. A. 1993. Effectiveness of flushing on reducing lead and copper levels in school drinking water. Environ Health Perspect. 101(3): 240-241

National Collaborating Centre for Environmental Health. (2019). Testing for lead in school drinking water: A summary of sampling protocols. Vancouver, B.C. Available at: http://www.ncceh.ca/ documents/guide/testing-lead-school-drinking-water-summarysampling-protocols [accessed 21 March 2019].

Ontario Ministry of the Environment. 2007. Flushing and testing for lead in drinking water.

Sanborn, L. H., \& Carpenter, A. T. 2018. A progress report on efforts to address lead by public school districts. Journal AWWA. 110(3): E18-E33. doi: 10.1002/awwa.1022.

United States Environmental Protection Agency. 2018. 3Ts for reducing lead in drinking water in schools and child care facilities: A training, testing, and taking action approach. Revised manual. Washington, DC: US EPA.

Verhougstraete, M. P., Gerald, J. K., Gerba, C. P., \& Reynolds, K. A. 2019. Cost-benefit of point-of-use devices for lead reduction. Environ Res. 171: 260-265. doi: 10.1016/j.envres.2019.01.016. 